\title{
Contribuição dos componentes e composição química de pastagens em sistemas forrageiros constituídos por diferentes leguminosas
}

\author{
Components contribution and chemical composition of pastures in forage \\ systems with different legumes
}

\author{
Clair Jorge Olivo ${ }^{\mathrm{I}}$ Edilene Steinwandter ${ }^{\mathrm{II}}$ Carlos Alberto Agnolin" Gilmar Roberto Meinerz ${ }^{\mathrm{II}}$ \\ Juliano Costa dos Santos" Claudia Marques de Bem ${ }^{\text {III }}$ Priscila Flores Aguirre ${ }^{\mathrm{III}}$ \\ Paulo Roberto Machado ${ }^{\text {III }}$ Tiago Luis da Ros de Araújo ${ }^{\text {III }}$
}

\section{RESUMO}

\begin{abstract}
Realizou-se o presente trabalho com o objetivo de avaliar a composição quimica de dois sistemas forrageiros, tendo como componentes comuns o capim-elefante, o azevém $e$ as espécies de crescimento espontâneo, variando em um sistema o consórcio com o trevo branco, e, em outro, com o amendoim forrageiro. Para avaliação, foram usados quatro piquetes com 0,25ha cada um. Como animais experimentais, foram utilizadas vacas em lactação da raça Holandesa. $O$ delineamento experimental utilizado foi o inteiramente casualizado, com dois tratamentos (sistemas forrageiros) $e$ duas repetições (piquetes). Para análise de proteina bruta (PB), fibra em detergente neutro (FDN) e fibra em detergente ácido (FDA), foram retiradas amostras através de simulação de pastejo. A participação dos componentes dos sistemas forrageiros variou segundo as leguminosas componentes. $O$ sistema composto por amendoim forrageiro permitiu suportar maior carga no período estival. Os valores médios (pré e póspastejo) para PB, FDN e FDA foram de 18,76; 71,46; 34,87\% para o sistema forrageiro constituído com o trevo branco e de 19,31; 71,19 e 35,40\%. Os resultados foram similares entre os sistemas forrageiros.
\end{abstract}

Palavras-chave: Arachis pintoi, fibra em detergente ácido, fibra em detergente neutro, Lolium multiflorum, Pennisetum purpureum, proteina bruta, Trifolium repens.

\section{ABSTRACT}

The aim of this research was to evaluate the chemical composition of two pasture-based systems having as common components the elephantgrass, ryegrass and spontaneous growth species, in one system the white clover and, in another system, the forage peanut. Four paddocks, each one with $0.25 \mathrm{ha}$, were used in the evaluation. Holstein cows were used in the evaluation. The experimental design was completely randomized, with two treatments (pasture-based systems), two replications (paddocks). To analyze the crude protein $(C P)$, neutral detergent fiber $(N D F)$ and acid detergent fiber $(A D F)$, hand-plucked samples were collected. Composition of forage systems changes according to its legumes compounds. Forage peanut system allowed a greater stocking rate in hot season. The mean values (pregraze and postgraze) of $C P, N D F$ and $A D F$, were $18.76 ; 71.46$ and $34.87 \%$ to the pasture-based system with white clover and 19.31; 71.19 and $35.40 \%$ to the system with forage peanut, respectively. Similar results were observed for the pasture systems.

Key words: acid detergent fiber, Arachis pintoi, crude protein, Lolium multiflorum, neutral detergent fiber, Pennisetum purpureum, Trifolium repens.

\section{INTRODUÇÃO}

$\mathrm{Na}$ atividade leiteira, o capim-elefante tem representado em diferentes regiões do País uma alternativa importante na alimentação dos animais (SILVA et al., 2002). No entanto, sua alta produtividade no período estival e a redução do crescimento no período hibernal, notadamente na Região Sul, devido à ocorrência de baixas temperaturas, podem resultar em grandes variações na produção e qualidade da forragem.

'Departamento de Zootecnia (DZ), Universidade Federal de Santa Maria (UFSM), 97105-900, Santa Maria, RS, Brasil. Email: clairo@smail.ufsm.br.*Autor para correspondência.

"Programa de Pós-graduação em Zootecnia, UFSM, Santa Maria, RS, Brasil.

${ }^{\text {IIIC }}$ urso de Zootecnia, UFSM, Santa Maria, RS, Brasil 
Na maioria das pesquisas, avalia-se o capimelefante especialmente no período estival, envolvendo, muitas vezes, o ápice de sua produção, entre o final da primavera e o verão, sendo poucas as referências que analisam essa forrageira no decorrer do ano agrícola (OLIVO et al., 2007). Nestas pesquisas, o capim-elefante normalmente é estabelecido de forma singular, sendo escassos os estudos que avaliam essa cultura em associação com outras espécies, visando à constituição de sistemas forrageiros (SOBCZAK et al., 2005). Seu consórcio com espécies como o azevém, o trevo branco e o amendoim forrageiro podem constituir-se em uma importante estratégia de produção de matéria seca, equilibrando a oferta e a qualidade de forragem (LADEIRA et al., 2002; LEITE et al., 2006; BRESOLIN et al., 2008). Essas espécies apresentam picos de produção em épocas distintas (GERDES et al., 2005), podendo aumentar a atividade microbiana do solo devido à alta proporção de compostos nitrogenados de seus componentes estruturais.

No contexto da atividade leiteira, que apresenta custos elevados de produção, devido, notadamente, à alta proporção de suplementação alimentar por litro de leite produzido, a utilização de pastos consorciados de gramíneas e leguminosas pode constituir uma alternativa viável, podendo aumentar a produção por vaca de $12 \mathrm{~kg} \mathrm{dia}^{-1}$ para 18 litros dia $^{-1}$ (SEGANFREDO,1995). Dentre as leguminosas, destacase o amendoim forrageiro, devido a sua elevada capacidade de rebrote e por apresentar valor nutritivo superior à maioria das leguminosas forrageiras (NASCIMENTO et al., 2004; BRESOLIN et al., 2008). Apesar desse potencial, são escassos os trabalhos que avaliam a composição nutricional dessa forrageira em consórcio com gramíneas sob condições de pastejo.

Nesse contexto, este trabalho foi conduzido com o objetivo de avaliar a composição química de dois sistemas forrageiros constituídos por capimelefante, azevém, espécies de crescimento espontâneo em consórcio com amendoim forrageiro ou com trevo branco, no decorrer de um ano agrícola.

\section{MATERIAL E MÉTODOS}

O trabalho foi conduzido no período de 24/04/07 a 30/04/08 em área experimental pertencente ao Departamento de Zootecnia da UFSM, situado na região da Depressão Central (Santa Maria, RS). O solo é classificado como argissolo vermelho eutrófico. No início do experimento, a análise de solo apresentou os seguintes valores médios: Índice SMP 5,7; P 14,5mg $\mathrm{dm}^{-3} ; \mathrm{K} 0,13 \mathrm{cmol}_{\mathrm{c}} \mathrm{dm}^{-3} ; \mathrm{Al}^{3+} 0,9 \mathrm{cmol}_{\mathrm{c}} \mathrm{dm}^{-3} ; \mathrm{Ca}^{2+} 5,5 \mathrm{cmol}_{\mathrm{c}}$ $\mathrm{dm}^{-3} ; \mathrm{Mg}^{2+} 2,3 \mathrm{cmol}_{\mathrm{c}} \mathrm{dm}^{-3} ; \mathrm{MO} 3,0 \%$; saturação de bases $54,0 \%$ e saturação por alumínio $12,2 \%$. O clima da região é o Cfa (subtropical úmido), conforme classificação de Köppen. As médias de temperatura e precipitação foram de $15,4^{\circ} \mathrm{C}$ e $128,8 \mathrm{~mm}$, respectivamente, para o período hibernal (caracterizado pela época de avaliação do azevém entre os meses de abril e outubro) e de $23,2^{\circ} \mathrm{C}$ e $151,95 \mathrm{~mm}$, respectivamente, para o período estival, semelhantes às médias normais da Região. Na região, há ocorrência de geadas nos meses de junho a agosto.

Os tratamentos foram constituídos por dois sistemas forrageiros, tendo como componentes comuns o capim-elefante (Pennisetum purpureum Schum.) cv. 'Merckeron Pinda', o azevém (Lolium multiflorum Lam.) cv. 'Comum' e as espécies de crescimento espontâneo, variando em um sistema o consórcio com o trevo branco (Trifolium repens L.) cv. 'Yi' (Sistema forrageiro 1) e, em outro, com o amendoim forrageiro (Arachis pintoi Krap. \& Greg.) cv. 'Amarillo' (Sistema forrageiro 2).

A área experimental utilizada foi de um hectare, com capim-elefante já estabelecido, desde 2004, em linhas distanciadas a cada $4 \mathrm{~m}$. Aárea foi subdividida em quatro piquetes de 0,25 ha cada. No final do mês de abril de 2007, em metade da área, entre as linhas constituídas pelas touceiras de capim-elefante, após gradagem do solo, foi estabelecido o trevo branco e o azevém, à razão de 3 e $30 \mathrm{~kg} \mathrm{ha}^{-1}$ de sementes, respectivamente. Nos outros dois piquetes, nas entrelinhas do capim-elefante, foi feita a sobressemeadura do azevém $\left(40 \mathrm{~kg} \mathrm{ha}^{-1}\right)$, considerando que o amendoim forrageiro já se encontrava estabelecido, desde dezembro de 2004, tendo sido utilizada a densidade de semeadura de $12 \mathrm{~kg} \mathrm{ha}^{-1}$. Para adubação, foram utilizados 60 e $100 \mathrm{~kg} \mathrm{ha}^{-1}$ de $\mathrm{P}_{2} \mathrm{O}_{5} \mathrm{e}$ $\mathrm{K}_{2} \mathrm{O}$, respectivamente, de acordo com análise do solo. Como adubação de cobertura, utilizou-se $100 \mathrm{~kg} \mathrm{ha}^{-1}$ $\mathrm{ano}^{-1}$ de nitrogênio, sob forma de uréia, parcelado em cinco aplicações, após o primeiro, terceiro, quinto, sétimo e nono pastejo. A utilização dos pastos foi iniciada no dia 15 de junho de 2007 e o último pastejo foi realizado no dia 26 de abril de 2008.

Os animais experimentais utilizados foram vacas em lactação da raça Holandesa, com peso vivo médio de $514 \pm 35,9 \mathrm{~kg}$ e produção média de leite de $20,80 \pm 2,23 \mathrm{~kg} \mathrm{dia}^{-1}$. As vacas permaneceram nas pastagens experimentais das 9 às $15 \mathrm{~h}$ e $30 \mathrm{~min}$ e das $18 \mathrm{~h}$ às $6 \mathrm{~h}$ e $30 \mathrm{~min}$, tendo sombra e água a disposição. $\mathrm{O}$ tempo de ocupação variou de um a dois dias. Fora das áreas experimentais, as vacas foram mantidas em pastagens da época, recebendo a mesma complementação alimentar. Durante o período hibernal, o critério de utilização da pastagem teve como base $o$ desenvolvimento do azevém, quando este se encontrava próximo a $20 \mathrm{~cm}$ de altura. No período estival, o critério foi a altura do capim-elefante, entre 80 
e $100 \mathrm{~cm}$. Antecedendo a entrada dos animais, estimouse a massa de forragem mediante a técnica de dupla amostragem (WILM et al., 1944), sendo realizado, em cada piquete, cinco cortes e 20 estimativas visuais nas linhas (touceiras) do capim-elefante, repetindo-se o processo nas entrelinhas. No capim-elefante, os cortes foram feitos a $50 \mathrm{~cm}$ do solo e, nas entrelinhas, rente ao solo.

$\mathrm{Na}$ estimativa da massa de forragem, considerou-se $25 \%$ da área ocupada pelo capim-elefante (linhas com $1 \mathrm{~m}$ de largura) e $75 \%$ ocupada pelas espécies presentes nas entrelinhas (linhas com $3 \mathrm{~m}$ de largura). Para cálculo da carga animal, procurou-se manter a oferta de forragem de $8 \mathrm{~kg}$ de MS por $100 \mathrm{~kg}$ de peso vivo para a massa de forragem verde da entrelinha e de $4 \mathrm{~kg}$ de MS por $100 \mathrm{~kg}$ de peso vivo para a massa de lâminas foliares de capim-elefante.

Para a determinação da composição química da pastagem, foram retiradas amostras, simulando o pastejo, mediante observação do comportamento ingestivo das vacas (EUCLIDES et al., 1992), uma em cada piquete, no início (entrada dos animais) e no final (antecedendo a retirada dos animais) de cada pastejo. Para análise, foram constituídas amostras do material presente na linha (capim-elefante) e na entrelinha. Nesta, foram retiradas amostras singulares do azevém e das leguminosas. Essas amostras foram secas em estufa e depois moídas $(1 \mathrm{~mm})$ em moinho do tipo Willey, acondicionadas e posteriormente analisadas pelo método de reflectância no infravermelho proximal NIRS (PIONEER, 1995) quanto a PB, FND e FDA.

$O$ delineamento experimental utilizado foi o inteiramente casualizado, com dois tratamentos (sistemas forrageiros), duas repetições de área (piquetes) e em parcelas subdivididas no tempo (ciclos de pastejo). Os dados foram submetidos à análise de variância e as médias comparadas pelo teste $\mathrm{F}$, ao nível de $5 \%$ de probabilidade do erro, e análise de correlação, através do coeficiente de Pearson. As variáveis que apresentaram interação entre tratamento e pastejos foram submetidas à análise de regressão polinomial. $\mathrm{O}$ modelo estatístico referente à análise das variáveis estudadas da pastagem foi representado por: $\mathrm{Y}_{\mathrm{ijk}}=\mathrm{m}+$ $T_{i}+R_{j}\left(T_{i}\right)+C_{k}+(T C)_{i k}+E_{i j k}$, em que: $Y_{i j k}$ representa as variáveis dependentes; $i$, índice de tratamentos (pastagens); j, índice de repetições (piquetes); $\mathrm{k}$, índice de pastejos; $m$ é a média de todas as observações; $T_{i}$ é o efeito dos tratamentos; $R_{j}\left(T_{i}\right)$ é o efeito de repetição dentro dos tratamentos (erro a); $\mathrm{C}_{\mathrm{k}}$ é o efeito dos ciclos de pastejo; (TC $)_{\mathrm{ik}}$ representa a interação entre os tratamentos e pastejos; $\mathrm{e}_{\mathrm{ijk}}$ é o efeito residual (erro b). As análises foram efetuadas com auxílio do pacote estatístico SAS (1997).

\section{RESULTADOS E DISCUSSÃO}

No decorrer do período experimental (371 dias), foram conduzidos 11 pastejos, com tempos de descanso de 28 a 34 dias para os períodos hibernal e estival, respectivamente, em ambos os sistemas forrageiros. Os valores de massa de forragem foram similares entre os tratamentos, sendo de 4,5 e 6,0t ha- ${ }^{-1}$ de MS para o pré-pastejo e de 3,68 e 3,59t ha ${ }^{-1}$ de MS para o pós-pastejo, nos períodos hibernal e estival, respectivamente. No sistema forrageiro em consórcio com o trevo branco, a participação dos principais constituintes da pastagem, durante o período hibernal, foi de 71,$69 ; 22,50 ; 3,37$ e $0,70 \%$ para o capim-elefante (CE), azevém (AZ), trevo branco (TB), e espécies de crescimento espontâneo (ECE), respectivamente. No período estival, essa participação foi de 52,77; 3,41 e $36,98 \%$ para o CE, TB e ECE, compostas especialmente por Paspalum conjugatum e papuã (Urochloa plantaginea), respectivamente. No sistema forrageiro em consórcio com o amendoim forrageiro (AF), a participação das principais espécies no período hibernal foi de 71,54;21,04; 1,68 e 1,89\% para o CE, AZ, $\mathrm{AF}$ e ECE, respectivamente. No período estival, foi de 50,$68 ; 13,15$ e $29,15 \%$ para o CE, AF e ECE, respectivamente. Com relação à lotação, houve similaridade entre os sistemas no período hibernal, sendo de 2,33 e 2,40 $\mathrm{UA} \mathrm{ha}^{-1}$ para as pastagens constituídas de trevo branco e amendoim forrageiro, respectivamente. No período estival, os valores foram de 3,72 e 4,47UA ha ${ }^{-1}$ para os respectivos tratamentos, havendo superioridade para o sistema em consórcio com amendoim forrageiro.

Quanto à composição química, para PB não houve diferença entre as pastagens, no período inicial, destacando-se o equilíbrio verificado entre as avaliações, proporcionado pelas diferentes espécies que constituíram os sistemas forrageiros (Tabela 1). Observa-se que a presença do azevém compensou o menor teor de PB do capim-elefante entre os meses de junho e agosto, embora essa condição tenha se invertido nas avaliações efetuadas em setembro e outubro. Condição similar foi obtida por OLIVO et al. (2007) ao verificar melhor valor nutritivo de folhas verdes do capim-elefante durante o período hibernal, em relação ao estival, verificando teores médios de $\mathrm{PB}$ superiores a $20 \%$. Segundo POLI (1992), ao se desenvolverem, as plantas elevam seus teores de MS, parede celular, celulose, fibra e lignina e diminuem os teores de PB e DIVMS, sendo que este comportamento é mais acentuado no verão, época em que o crescimento das plantas tropicais é mais intenso em relação ao inverno. TOWNSEND et al. (1994), trabalhando com a 
Tabela 1 - Composição química da forragem, no período inicial do pastejo, em dois sistemas forrageiros (SF) constituídos por $\mathrm{CE}+\mathrm{TB}+\mathrm{AZ}$ $+\mathrm{ECE}(\mathrm{SF} 1)$ e $\mathrm{CE}+\mathrm{AF}+\mathrm{AZ}+\mathrm{ECE}(\mathrm{SF} 2)$.

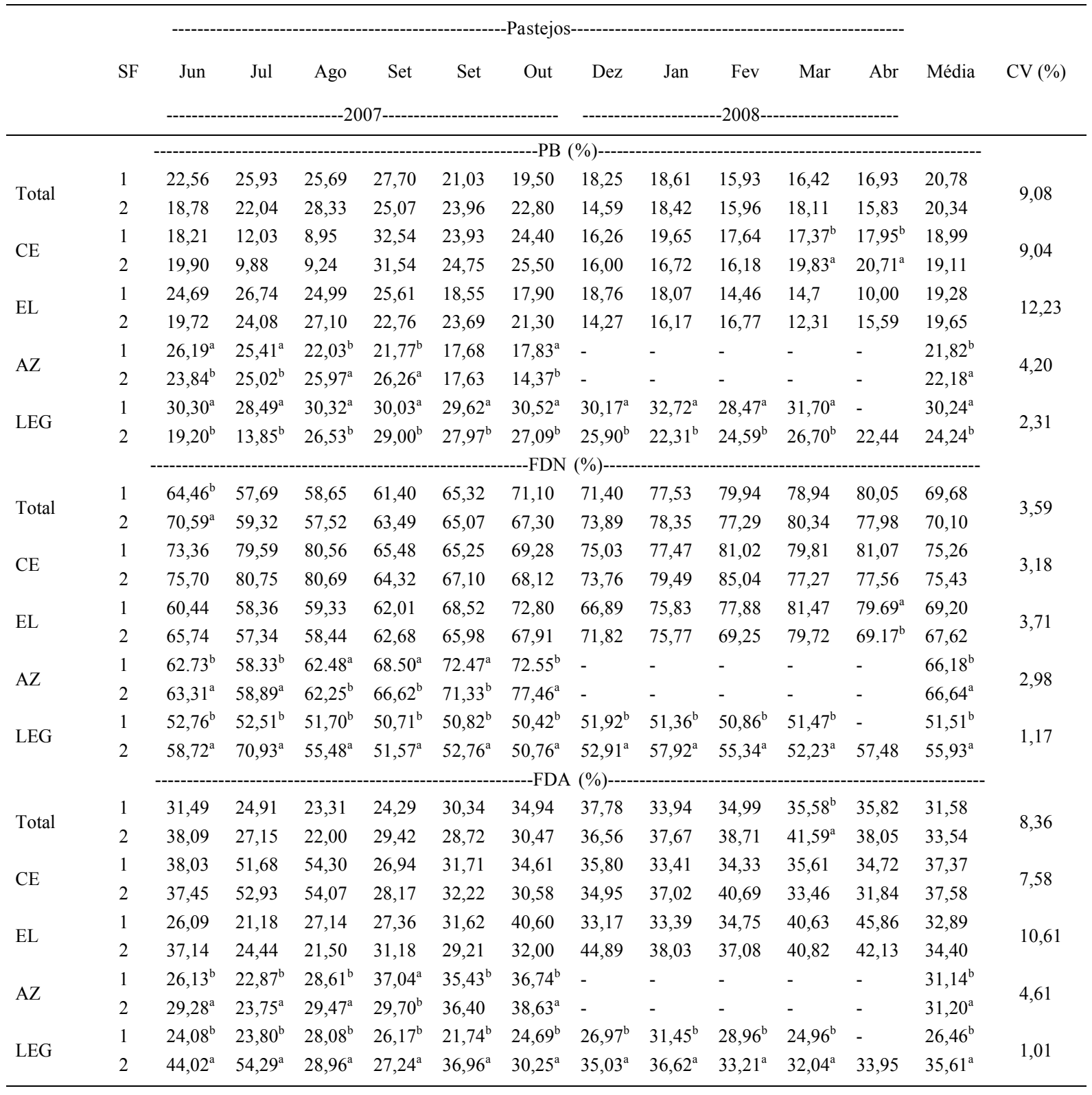

Amostras de pastejo simulado.

' $a$ b' médias seguidas por letras distintas na coluna, entre os sistemas forrageiros, diferem entre si $(\mathrm{P}<0,05) ; \mathrm{CE}=$ capim-elefante; $\mathrm{TB}=$ trevo branco (LEG 1); AZ = azevém; ECE = espécies de crescimento espontâneo; $\mathrm{AF}$ = amendoim forrageiro (LEG 2); Total = total da pastagem; $\mathrm{EL}=$ entrelinha; $\mathrm{LEG}=$ leguminosas; $\mathrm{PB}=$ proteína bruta; $\mathrm{FDN}=$ fibra em detergente neutro; FDA = fibra em detergente ácido. No mês de setembro, foram realizados dois pastejos.

mesma cultivar de capim-elefante, verificaram, em uma sequência de três ciclos de pastejo, de novembro a março, teores de PB de 8,$9 ; 11,0$ e 10,9\%, também por simulação de pastejo, confirmando essa tendência de melhor qualidade na porção comestível em períodos de menor crescimento dessa forrageira.
$\mathrm{O}$ valor médio de $\mathrm{PB}$ encontrado na massa de forragem da entrelinha $(19,46)$ foi similar ao da pastagem $(20,56)$, devido à presença do azevém e das leguminosas, compensando o menor valor nutritivo das espécies de crescimento espontâneo. Comparando-se as leguminosas, o trevo branco apresentou teor de $\mathrm{PB}$ 
superior $(\mathrm{P}<0,05)$ ao amendoim forrageiro. Esse resultado é esperado para forrageiras de estação fria que normalmente apresentam melhor valor nutritivo em relação às forrageiras tropicais (LEITE et al., 2006). Valores semelhantes para a PB das leguminosas foram observados por AFFONSO et al. (2007).
Para o azevém, verificou-se teor médio de PB superior $(\mathrm{P}<0,05)$ no tratamento constituído por amendoim forrageiro, possivelmente devido à maior contribuição de massa de forragem dessa leguminosa em relação à do trevo branco. Foram observados, no período final (Tabela 2) de pastejo, valores médios de

Tabela 2 - Composição química da forragem no período final do pastejo, em dois sistemas forrageiros (SF) constituídos por CE + TB + AZ + $\mathrm{ECE}(\mathrm{SF} 1)$ e $\mathrm{CE}+\mathrm{AF}+\mathrm{AZ}+\mathrm{ECE}(\mathrm{SF} 2)$.

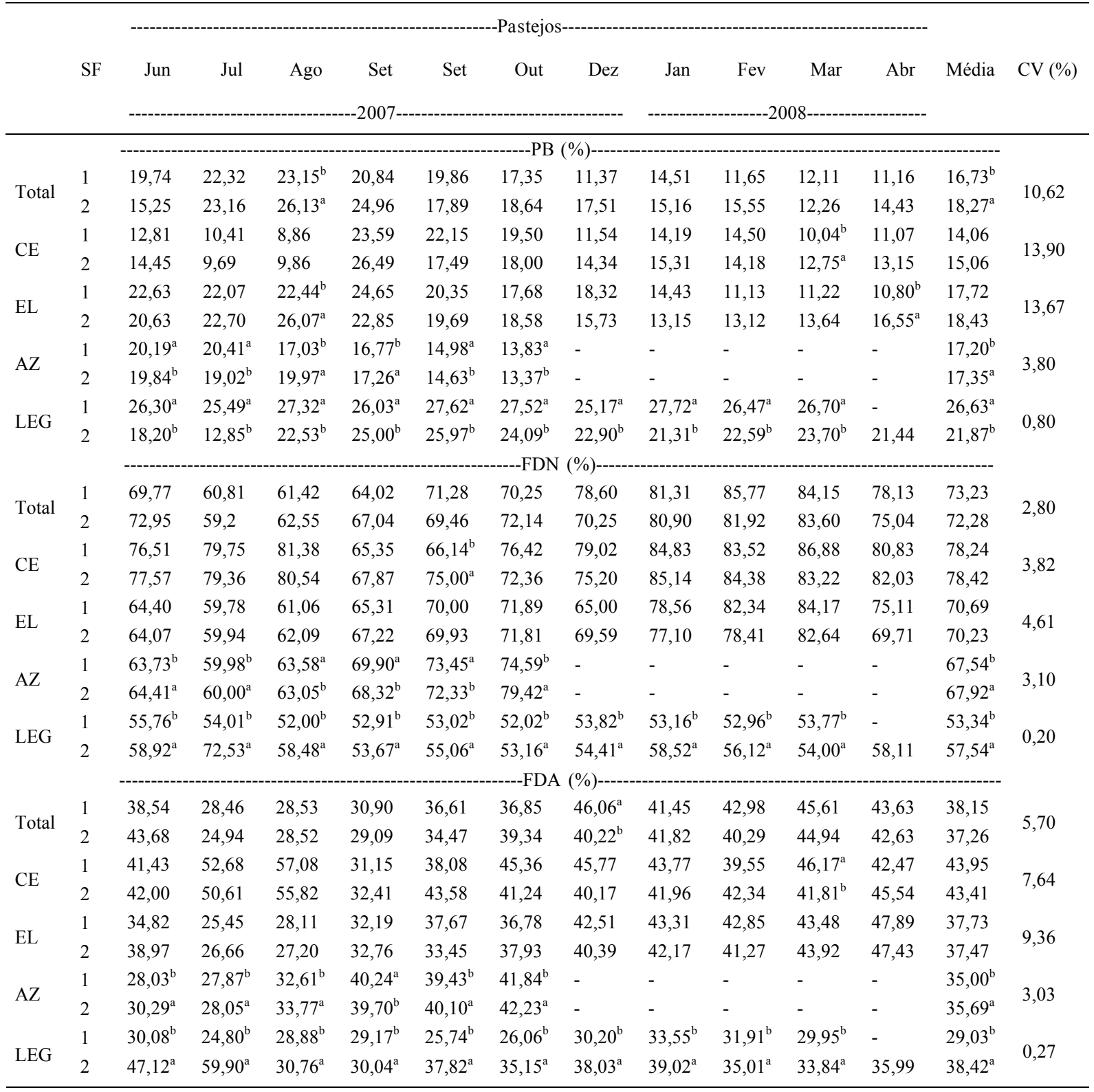

Amostras de pastejo simulado.

' $a$ b' médias seguidas por letras distintas na coluna, entre os sistemas forrageiros, diferem entre si $(\mathrm{P}<0,05)$; $\mathrm{CE}=$ capim-elefante; TB = trevo branco (LEG 1); AZ = azevém; ECE = espécies de crescimento espontâneo; $\mathrm{AF}=$ amendoim forrageiro (LEG 2); Total = total da pastagem; $\mathrm{EL}=$ entrelinha; $\mathrm{LEG}=$ leguminosas; $\mathrm{PB}=$ proteína bruta; FDN = fibra em detergente neutro; FDA = fibra em detergente ácido. No mês de setembro, foram realizados dois pastejos. 
PB no azevém de 17,20 e 17,35\% para os sistemas com trevo branco e amendoim forrageiro, respectivamente. Valores médios, semelhantes ao do presente trabalho, com média de $17,52 \%$, foram relatados por ROCHA et al. (2003) em amostras de pastejo simulado, em pastagem de azevém adubado com $150 \mathrm{~kg} \mathrm{ha}^{-1}$ de $\mathrm{N}$ sob pastejo contínuo.

A partir da análise de regressão, verificouse para a PB do azevém, comportamento linear $(\mathrm{y}=31,36$ $0,079 \mathrm{x} ; \mathrm{r}=0,92 ; \mathrm{P}<0,0001)$ em consórcio com trevo branco e quadrático $\left(\mathrm{y}=7,18+0,391 \mathrm{x}-0,00198 \mathrm{x}^{2} ; \mathrm{r}=0,88\right.$; $\mathrm{P}<0,0001)$ em consórcio com o amendoim forrageiro. A redução observada dos teores de PB no final do ciclo do azevém é explicada pela maior fração de material senescente, maior proporção de colmos com considerável desenvolvimento de tecidos estruturais, diminuindo a relação folha/colmo. Essa assertiva pode ser confirmada pela correlação negativa verificada entre a PB e a massa de forragem de colmo mais bainha do azevém $(\mathrm{r}=-0,95 ; \mathrm{P}<0,0001)$. No final dos pastejos (Tabela 2), observa-se que os valores mantiveram-se elevados, guardando proporcionalidade com os teores verificados nas amostras do início do pastejo. Os teores de PB mais baixos e de FDN mais elevados no final do pastejo refletem a maior proporção de lâminas foliares que foram removidas na dieta selecionada pelos animais. Trabalhos conduzidos com forrageiras estabelecidas singularmente normalmente demonstram maior variabilidade dos dados (LIMA et al. (2004).

Observa-se que os teores médios de PB, tanto no início quanto no final de utilização das pastagens, são adequados para atender as exigências nutricionais de vacas de 454 e $680 \mathrm{~kg}$ de $P V$ e produção de leite de 20 e 35 litros dia $^{-1}$, respectivamente, considerando-se que o teor de nutrientes digestíveis totais da dieta esteja próximo a $68 \%$ (NRC, 2001).

Os valores de FDN das amostras totais simuladas (Tabela1 e 2) foram similares entre as pastagens, com declínio no período hibernal e aumento no período estival. A análise de regressão revelou esse comportamento, tanto no sistema constituído de trevo branco ( $\left.\mathrm{y}=85,63-0,526 \mathrm{x}+0,00253 \mathrm{x}^{2} ; \mathrm{r}=0,89 ; \mathrm{P}<0,001\right)$ quanto por amendoim forrageiro $(\mathrm{y}=97,09$ $\left.0,632 \mathrm{x}+0,00266 \mathrm{x}^{2} ; \mathrm{r}=0,70 ; \mathrm{P}=0,0047\right)$. O teor médio de FDN, considerando-se os valores de início e de final de pastejo, foi de 71,32\%. GERDES et al. (2005), estudando misturas forrageiras, encontraram teores médios de $69,5 \%$ de FDN em seis pastejos, para a mistura de capim-aruana (Panicum maximum) com aveia preta e azevém, utilizando $200 \mathrm{~kg} \mathrm{ha}^{-1} \mathrm{ano}^{-1} \mathrm{de}$ nitrogênio. DERESZ et al. (2006), trabalhando com a cultivar Napier, adubado com $200 \mathrm{~kg} \mathrm{ha}^{-1} \mathrm{ano}^{-1}$ de nitrogênio, manejado sob sistema de pastejo rotacionado, com 30 dias de descanso e três de ocupação, observaram em amostras de pastejo simulado, na entrada dos animais na pastagem, teor médio de FDN de 69,14\%. DESCHAMPS (1999) estudando as modificações químicas da parede celular de capim-elefante ao longo do crescimento, em 126 dias, obteve, em lâminas foliares, aos 28 dias de idade, teores de FDN de $79 \%$, valor superior aos encontrados no presente trabalho.

Comparando-se os principais componentes da pastagem, observa-se que as maiores variações devem-se às leguminosas, verificando-se diferenças em todos os pastejos em que foi possível fazer a comparação e, na média, com teores mais elevados no amendoim forrageiro. Os maiores valores de FDN foram observados no capim-elefante. Valores similares foram verificados por LIMA et al. (2004), que obtiveram teores de 76,3 e $75,1 \%$ para as folhas de capim-elefante cv. 'Guaçu' no pré e pós-pastejo, respectivamente, com ciclos de pastejo de 44 dias e adubação nitrogenada de $250 \mathrm{~kg} \mathrm{ha}^{-1}$ ano $^{-1}$.

Resposta similar a FDN foi obtida com relação a FDA e esses resultados foram observados tanto nas amostras retiradas no início como no final dos pastejos (Tabela1 e 2). Observa-se que os menores valores de FDA foram encontrados no tratamento constituído por trevo branco. Os valores médios de FDA de 37\%, verificados para o capim-elefante podem ser considerados baixos, quando comparado ao observado por MARTINS-COSTA et al. (2008), que encontraram valor médio, no período de um ano, de $44,20 \%$, com intervalo de corte do capim a cada 30 dias.

\section{CONCLUSÃO}

As pastagens apresentam composição química similar, apontando para um sinergismo entre as espécies de gramíneas e leguminosas em cada sistema forrageiro. Os consórcios constituídos por capim-elefante, azevém, espécies de crescimento espontâneo, trevo branco ou amendoim forrageiro proporcionam baixa variação entre os pastejos, no decorrer do ano.

\section{AGRADECIMENTOS}

À Fundação de Amparo à Pesquisa do Estado do Rio Grande do Sul (FAPERGS), pela concessão de bolsa de iniciação científica; e à Empresa MATSUDA pela doação de sementes de amendoim forrageiro.

\section{REFERÊNCIAS}

AFFONSO, A. et al. Rendimento e valor nutritivo da forragem outonal de amendoim forrageiro. Ciência Animal Brasileira, 
Goiânia, v.8, n.3, p.385-395, 2007. Disponível em: <http:// www.revistas.ufg.br/index.php/vet/article/view/1676/1646>. Acesso em: 13 out. 2010.

BRESOLIN, A.P.S. et al. Tolerância ao frio do amendoim forrageiro. Ciência Rural, Santa Maria, v.38, n.4, p.11541157, 2008. Disponível em: <http://www.scielo.br/ scielo.php? script=sci_arttext \& pid=S 0103 $84782008000400041 \& \operatorname{lng}=\mathrm{pt} \overline{\mathrm{nrm}}=\mathrm{iso}>$. Acesso em: 12 out. 2010. doi: 10.1590/S0103-84782008000400041.

DERESZ, F. et al. Composição química, digestibilidade e disponibilidade de capim-elefante cv. Napier manejado sob pastejo rotativo. Revista Brasileira de Zootecnia, Viçosa, v.35, n.3, p.863-869, 2006. Disponível em: <http://www.scielo.br/ scielo.php? script=sci arttext\&pid=S 1516 $35982006000300032 \& \operatorname{lng}=\mathrm{en} \&{ }_{n}{ }^{-}=\mathrm{r}=\mathrm{iso}>$. Acesso em: 12 out. 2010. doi: $10.1590 / \mathrm{S} 1516-35982006000300032$.

DESCHAMPS, F.C. Implicações do período de crescimento na composição química e digestão dos tecidos de cultivares de capimelefante (Pennisetum purpureum Schum.). Revista Brasileira de Zootecnia, Viçosa, v.28, n.6, p.1358-1369, 1999.

EUCLIDES, V.P.B. et al. Avaliação de diferentes métodos de amostragens sob pastejo. Revista Brasileira de Zootecnia, Viçosa, v.21, n.4, p.691-702, 1992.

GERDES, L. et al. Composição química e digestibilidade da massa de forragem em pastagem irrigada de capim-aruana exclusivo ou sobre-semeado com mistura de aveia preta e azevém. Revista Brasileira de Zootecnia, Viçosa, v.34, n.4, p.1098-1108, 2005. Disponível em: <http://www.scielo.br/ scielo.php? script $=$ sci arttext\&pid=S 1516 $35982005000400003 \& \operatorname{lng}=\mathrm{en} \& \overline{\mathrm{nrm}}=\mathrm{iso}>$. Acesso em: 12 out. 2010. doi: $10.1590 / \mathrm{S} 1516-35982005000400003$.

LADEIRA, M.M. et al. Avaliação do feno de Arachis pintoi utilizando o ensaio de digestibilidade in vivo. Revista Brasileira de Zootecnia, Viçosa, v.31, n.6, p.2350-2356, 2002. Disponível em: <http://www.scielo.br/ scielo.php? script=sci_arttext \& pid=S 1516 $35982002000900025 \& \operatorname{lng}=$ en $\overline{k r m}=\mathrm{iso}>$. Acesso em: 12 out. 2010 . doi: 10.1590/S1516-35982002000900025.

LEITE, D.M.G. et al. Efeito de diferentes sistemas de pastejo sobre o desempenho de suínos mantidos em pastagem de trevo-branco (Trifolium repens L.). Revista Brasileira de Zootecnia, Viçosa, v.35, n.3, p.792-796, 2006. Disponível em: <http://www.scielo.br/ scielo.php?script $=$ sci arttext\&pid $=$ S151635982006000300022\&lng $=$ en\&nrm=iso $>$. Acesso em: 12 out. 2010. doi: 10.1590/S151635982006000300022 .

LIMA, M.L.P. et al. Concentração de nitrogênio uréico plasmático (nup) e produção de leite de vacas mestiças mantidas em gramíneas tropicais sob pastejo rotacionado. Revista Brasileira de Zootecnia, Viçosa, v.33, n.6, p.1616-1626, 2004. Disponível em: <http://www.scielo.br/ scielo.php? script=sci arttext\&pid=S 1516 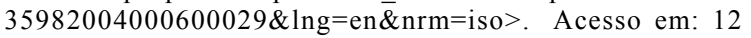 out. 2010 . doi: $10.1590 / \mathrm{S} 1516-35982004000600029$.

MARTINS-COSTA, R.H.A. et al. Valor nutritivo do capimelefante obtido em diferentes idades de corte. Revista Brasileira de Saúde e Produção Animal, Salvador, v.9, n.3, p.397-406, 2008. Disponível em: http://revistas.ufba.br/index.php/rbspa/ article/view/1397/660. Acesso em: 13 out. 2010.

NASCIMENTO, J. et al. Avaliação quantitativa e qualitativa da fitomassa de leguminosas para uso como cobertura de solo. Ciência Rural,
Santa Maria, v.34, n.3, p.947-949, 2004. Disponível em: <http:// www.scielo.br/scielo.php?script=sci_arttext\&pid=S010384782004000$300047 \& \operatorname{lng}=$ t\& $\&$ rm $=$ iso $>$. Acesso em: 12 out. 2010. doi: 10.1590/ S0103-84782004000300047.

NRC - NATIONAL RESEARCH COUNCIL. Nutrient requeriments of dairy cattle. 7.ed. Washinton, D.C.: National Acadeny Science, 2001. 381p.

OLIVO, C.J. et al. Produtividade e valor nutritivo de pasto de capim-elefante manejado sob princípios agroecológicos. Revista Brasileira de Zootecnia, Viçosa, v.36, n.6, p.1729-1735, 2007. Disponível em: <http://www.scielo.br/ scielo.php? script=sci_arttext \& pid=S 1516 $35982007000800004 \& \operatorname{lng}=\mathrm{pt} \& \mathrm{nrm}=\mathrm{iso}>$. Acesso em: 12 out. 2010. doi: 10.1590/S1516-35982007000800004.

PIONEER. Pioner forage manual - a nutritional guide. Iowa: Pioneer Hi-Bred International, 1995. 54p.

POLI, C.H.E.C. Desenvolvimento morfológico, produção de forragem, proteína bruta e digestibilidade in vitro de cinco cultivares de capim-elefante (Pennisetum purpureum, Schum.). 1992. 148f. Dissertação (Mestrado em Zootecnia) - Faculdade de Agronomia, Universidade Federal do Rio Grande do Sul, Porto Alegre, RS.

ROCHA, M.G. et al. Alternativas de utilização da pastagem hibernal para recria de bezerras de corte. Revista Brasileira de Zootecnia, Viçosa, v.32, n.2, p.383-392, 2003. Disponível em: $<$ http://www.scielo.br/scielo.php?script=sci_arttext\&pid=S1516$35982003000200017 \& \operatorname{lng}=$ pt\&nrm=iso $>$. Acesso em: 12 out. 2010. doi: $10.1590 / \mathrm{S} 1516-35982003000200017$.

SAS - STATISTICAL ANALYSIS SYSTEM. User's guide: statistics. Version 6.11. Cary, 1997. 1187p.

SEGANFREDO, M.A. Leguminosas de verão: capacidade para fixação simbiótica de nitrogênio e potencial de utilização no sul do Brasil. Ciência Rural, Santa Maria, v.25, n.3, p.481487, 1995. Disponível em: <http://www.scielo.br/ scielo.php?script $=$ sci_arttext\&pid=S010384781995000300027 $\& \operatorname{lng}=$ pt\&nrm=iso $>$. Acesso em: 12 out. 2010. doi: 10.1590/ S0103-84781995000300027.

SILVA, M.M.P. et al. Composição bromatológica, disponibilidade de forragem e índice de área foliar de 17 genótipos de capimelefante (Pennisetum purpureum Schum.) sob pastejo, em Campos de Goytacazes, R.J. Revista Brasileira de Zootecnia, Viçosa, v.31, n.1, p.313-320, 2002. (suplemento). Disponível em: <http:/ /www.scielo.br/scielo.php?script $=$ sci_arttext\&pid $=$ S1516$35982002000200004 \& \operatorname{lng}=\mathrm{pt \& nrm}=\mathrm{iso}>$. Acesso em: 12 out. 2010. doi: $10.1590 /$ S1516-35982002000200004.

SOBCZAK, M.F. et al. Evaluation of an elephant grass pasture mixed with black oats managed under agro ecological principles in the winter period. Livestock Research for Rural Development. Cali, v.17, n.6, 2005. Disponível em: $<$ http:// www.lrrd.org//rrd17/6/fati17071.htm>. Acesso em: 22 set. 2010.

TOWNSEND, C.R. et al. Desempenho de novilhas da raça Holandesa em cultivares de capim-elefante (Pennisetum purpureum Schum.). Ciência Rural, Santa Maria, v.24, n.2, p.381-386, 1994.

WILM, H.G. et al. Estimating forage yield by the double sampling method. Journal of the American Society for Agriculture, Geneva, v.36, n.1, p.194-203, 1944. 